\title{
Physical Properties of Halloysite Nanotubes-Polyvinyl Alcohol Nanocomposites Using Malonic Acid Crosslinked
}

\author{
(Sifat-sifat Fizikal Nanotiub Hallosit-Polivinil Alkohol Nanokomposit Menggunakan Asid Malonik Tersilang) \\ Tayser Sumer Gaaz* \& Emad Kamil Hussein \\ Technical College Al-Musaib, Al-Furat Al-Awsat Technical University, Iraq \\ Ahmed A. Al-Amiery \\ Energy and Renewable Energies Technology Centre, University of Technology, Iraq
}

\begin{abstract}
Halloysite nanotubes (HNTS) based nanocomposites were produced by blending individualized HNTs dispersion with polyvinyl alcohol (PVA). Several sequential separation techniques were applied to obtain stable individualized HNTs dispersion. The preparation of PVA-crosslinked-HNTS nanocomposite has not been developed and, to the best of our knowledge, there was no published report indicating the use of neither dispersion nor crosslinker agent. In addition, PVA was crosslinked using the crosslinker malonic acid (MA) and sulfuric acid as a catalyst. This individualization increases the mechanical and thermal properties of HNTS-PVA nanocomposites. As a side result, crosslinking was employed to make PVA water-insoluble and hence to become more useful in biomedical applications. Examination of the nanocomposites indicated that HNTs were uniformly dispersed in both PVA as well as crosslinked PVA. These nanocomposites could be composted easily and hence would be good candidates tolreplace some of today's traditional non-biodegradable plastics that end up in landfills.
\end{abstract}

Keywords: Nanostructures; Polymer nanocomposites; Thermal properties; Nanocomposites

\section{INTRODUCTION}

Halloysite nanotubes (HNTs) whose chemical formula is $\mathrm{Al}_{2} \mathrm{Si}_{2} \mathrm{O}_{5}(\mathrm{OH})_{4} \cdot \mathrm{nH}_{2} \mathrm{O}$ are formed by rolling the sheet to form a tabular structure. HNTs can be found in many countries and it is mined from the natural deposit (Liu et al. 2007; Joussein et al. 2005). The letter " $n$ " appears in the formula refers to two types of HNTs: $\mathrm{n}=0$ for halloysite- $7 \AA$ and $\mathrm{n}=2$ for hydrated halloysite- $10 \AA$. The name halloysite is extracted from the rolling process of the structure (Joussein et al. 2005). Despite the fact that HNTs has a definite formula, its formula could change due to the impurities such as sulfur, iron oxides and others (Joussein et al. 2005). HNTs occur widely in weathered rocks as well as in soils and appear to have alternation of a wide variety of igneous and non-igneous rocks (Liu et al. 2007; Joussein et al. 2005). The uses of HNTs extend from bioreactor, catalysts, time-release capsules, filler, and templates for depositing other nanoparticles, polymer filler or property (Liu et al. 2007; Ahmad et al. 2016).

As a filler, HNTs are used in reinforcement the polymer matrix such as polypropylene, polyamide, epoxy resin, ethylene propylene diene monomer rubber, and styrene rubber. These nanocomposites are characterized as having good mechanical and thermal properties; however they are not biodegradable (Liu et al. 2007; Ye et al. 2007; Deng et al. 2008; Ning et al. 2007; Du et al. 2006; Marney et al. 2008; Du et al. 2008; Guo et al. 2008; Pasbakhsh et al. 2010). HNTs are very effective fillers such as adding HNTs to soy protein improves the fire resistance (Nakamura et al. 2013). As another example, PVA which has relatively low strength and thermal stability for some applications could become different polymer with excellent mechanical properties and thermal stability mainly due to the thermal stability of HNTs. HNTS-PVA nanocomposites have reported having excellent mechanical properties which could extend the use of PVA to variety of applications in industry (Zhou et al. 2010).

In this paper, HNTs individualization is discussed in addition to crosslinking of PVA in order to achieve much better properties. The crosslinking technique is normally used to improve the mechanical and thermal properties in addition to improve the solubility of many polymers (Yeom \& Lee 1996; Zhang et al. 2010). In addition to PVA as a crosslinker, glyoxal glutaraldehyde is the other universally crosslinker for polymers that primarily contain amine groups such as proteins (Yeom \& Lee 1996; Zhang et al. 2010). Other attempts have shown that crosslinking of PVA can be performed by utilizing dicarboxylic acids such as a malonic acid (MA) with sulphuric acid (Takip et al. 2015) which is widely considered as a catalyst to obtain esterification (Jian \& Ming 1987; Majumdar \& Adhikari 2006).

The applications of HNTs cover medical and technology. In the medical field, the most attractive field, adding thin HNTs layers resulted in improved adhesion matrix of human dermal fibroblasts (Lvov \& Abdullayev 2013). In the environmental sector, HNTs present several biological and non-biological uses, such as a diuretic drug transportation to remove hazardous species (Chang et al. 2011). HNTs are decisive inorganic constituents for the nanotechnology of composite biomaterials in diversely vital biomedical disciplines including corrosion protection implant alloys, biosensors, tunable drugs delivery, transportation systems, and biocide agents (Deen \& Zhitomirsky 2014). A series of 
very exciting new applications of HNTs in the medical field such as bone implants and cancer cell isolation has been recently added (Rong et al. 2016).

Generally, the crosslink, as a technique, has not been used in many research and there is a limited number of investigations are reported. In the study, HNTs are individualized using several techniques and the resulting membrane-as biodegradable HNTs-PVA nanocomposites are then fabricated. These thin membrane-like nanocomposites are characterized by smooth surfaces while their thermal and tensile properties are excellent. PVA and its counterpart nanocomposites HNTs-PVA were crosslinked-using MA - the process that is conducted using sulfuric acid as catalyst. One of the most important achievements for PVA-crosslinking is that HNTS-PVA composites is characterized as water-insoluble. It is important to note that using MA crosslinked HNTs-PVA composites shows much better improvement of the thermal and mechanical properties.

\section{MATERIALS AND METHODS}

\section{INDIVIDUALIZATION OF HNTS}

The individualization of the samples was performed throughout steps as shown in Table 1. HNTs were purchased from Natural Nano, New York. HNTs were initially added into distilled water at a weight ratio of 1:49. Sodium Dodecyl Sulfate (SDS) (Mw 288.38, $\mathrm{C}_{12} \mathrm{H}_{25} \mathrm{NaO}_{4} \mathrm{~S}$ ) was supplied by BioShop Canada Inc., Burlington, L7L6A4) (HNT: SDS (w/w) $=10: 1)$. SDS was then added to the mixture, as a non-ionic surfactant, to help individualize the HNTs. The $\mathrm{pH}$ value of the mixture was adjusted to 10 to further avoid clustering of HNTs (Qiu 2012). The mixture (at $\mathrm{pH}=10$ ) was stirred using mechanical stirrer at $90^{\circ} \mathrm{C}$ and $1000 \mathrm{rpm}$ for $1 \mathrm{hr}$ and followed by ultrasonication (WiseClean ${ }^{\circledR}$, Ultrasonic Cleaner, Model WUC-A10H \& WUC-A22H, Seoul, Korea) of the final mixture at $65^{\circ} \mathrm{C}$ for $1 \mathrm{hr}$ to form original HNTs dispersion. The original HNTs dispersion was kept standing for 2 days until it was stabilized. The supernatant of the HNTs dispersion was used as final individualized HNTs dispersion while the solution at the bottom with HNTs deposition was removed. The HNTs content in the final individualized HNTs dispersion was 0.5 wt. $\%$.

TABLE 1. Composition of individualization of HNTs simple example of a table

\begin{tabular}{lcc}
\hline \multicolumn{1}{c}{ Samples } & Step I & Step II \\
\hline $\begin{array}{l}\text { Individualization } \\
\text { of HNTs }\end{array}$ & HNTs $(1.0 \mathrm{~g})+\mathrm{H}_{2} \mathrm{O}(49 \mathrm{~g})$ & + SDS $(0.1 \mathrm{~g})$ \\
\hline
\end{tabular}

PREPARATION OF HNT-PVA AND HNT-PVA CROSSLINKED USING MA

The preparation of the samples was performed throughout steps as shown in Table 2. PVA powder (Mw 89,000-98,000, $99+\%$ hydrolysed) was supplied by Sigma-Aldrich. PVA was added to the distilled water at a weight ratio of 1:9 to form PVA solution which was maintained in a water bath at $80^{\circ} \mathrm{C}$ and stirred for 30 min. MA powder (ReagentPlus ${ }^{\circledR}$, 99\%, Sigma-Aldrich, St. Louis, MO) was then added to the PVA solution. The weight ratio of MA and PVA was 1:10. The $\mathrm{pH}$ value of the mixture was adjusted at 1 (Acidic) by adding sulfuric acid (ACS reagent, 95-98\% $\mathrm{H}_{2} \mathrm{SO}_{4}$ ) was supplied by Sigma-Aldrich. The mixture was stirred at $90^{\circ} \mathrm{C}$ for 1 hour for procuring.

TABLE 2. Simple example of a table

\begin{tabular}{lcc}
\hline \multicolumn{1}{c}{ Samples } & Step I & Step II \\
\hline HNT-PVA and HNT- & PVA $(1.0 \mathrm{~g})+\mathrm{H}_{2} \mathrm{O}(9.0 \mathrm{~g})$ & $+\mathrm{MA}(0.1 \mathrm{~g})$ \\
PVA crosslinked & & \\
using MA & & \\
\hline
\end{tabular}

FABRICATION OF HNT-PVA NANOCOMPOSITES

The PVA solution was added to the final individualized HNTs dispersion at desired PVA to HNTs weight ratios. The HNTs dispersion and PVA solution mixtures were stirred at $90^{\circ} \mathrm{C}$ for $1 \mathrm{hr}$ and slowly dried in an oven at $40^{\circ} \mathrm{C}$ to form HNTs-PVA nanocomposite.

PREPARATION OF CROSSLINKED HNT-PVA NANOCOMPOSITES USING MA

The preparation of the samples was performed throughout steps as shown in Figure 1. The PVA solution was added to the final individualized HNTs dispersion at desired PVA and HNTS weight ratios. The HNTs dispersion and PVA solution mixtures were stirred at $90^{\circ} \mathrm{C}$ for $1 \mathrm{hr}$ and ultrasonicated at $65^{\circ} \mathrm{C}$ for $1 \mathrm{hr}$. MA powder (ReagentPlus ${ }^{\circledR}, 99 \%$, Sigma-Aldrich, St. Louis, MO) was then added to the mixtures. The weight ratio of MA to PVA was $1: 10$. The $\mathrm{pH}$ values of the mixtures were adjusted to 1 (Acidic) by adding crosslinking catalyst sulfuric acid (ACS reagent, 95-98\% $\mathrm{H}_{2} \mathrm{SO}_{4}$ ) was supplied by Sigma-Aldrich. The mixtures were stirred at $90^{\circ} \mathrm{C}$ for $1 \mathrm{hr}$ for procuring. The crosslinked HNTs-PVA nanocomposites were then immersed in distilled water at room temperature for $12 \mathrm{hr}$ until the system was stabilized in order to partially remove sulfuric acid, remaining MA and uncrosslinked PVA. The water-immersed and cured crosslinked HNTs-PVA nanocomposites then dried at $40^{\circ} \mathrm{C}$ to form final crosslinked HNTs-PVA nanocomposites.

\section{CHARACTERIZATION}

The morphology of the nanotube was tested using the Field Emission Scanning Electron Microscope (FESEM) (ZEISS SUPRA 55-VP) of high resolution and low charging on the sample surface and fortified by the Elemental Analysis was used OXFORD EDS and Mapping. The magnification of morphology observations for clearer images takes place at ranges of 10, 25, 50, 100 and $200 \mathrm{k}$.

Chemical analysis of HNTs-PVA nanocomposites along with MA crosslinked samples are tested using FTIR spectrophotometer (Nicolet Magna-IR 560, Thermo Scientific, Waltham, MA). An average spectra over 64 scans were taken 


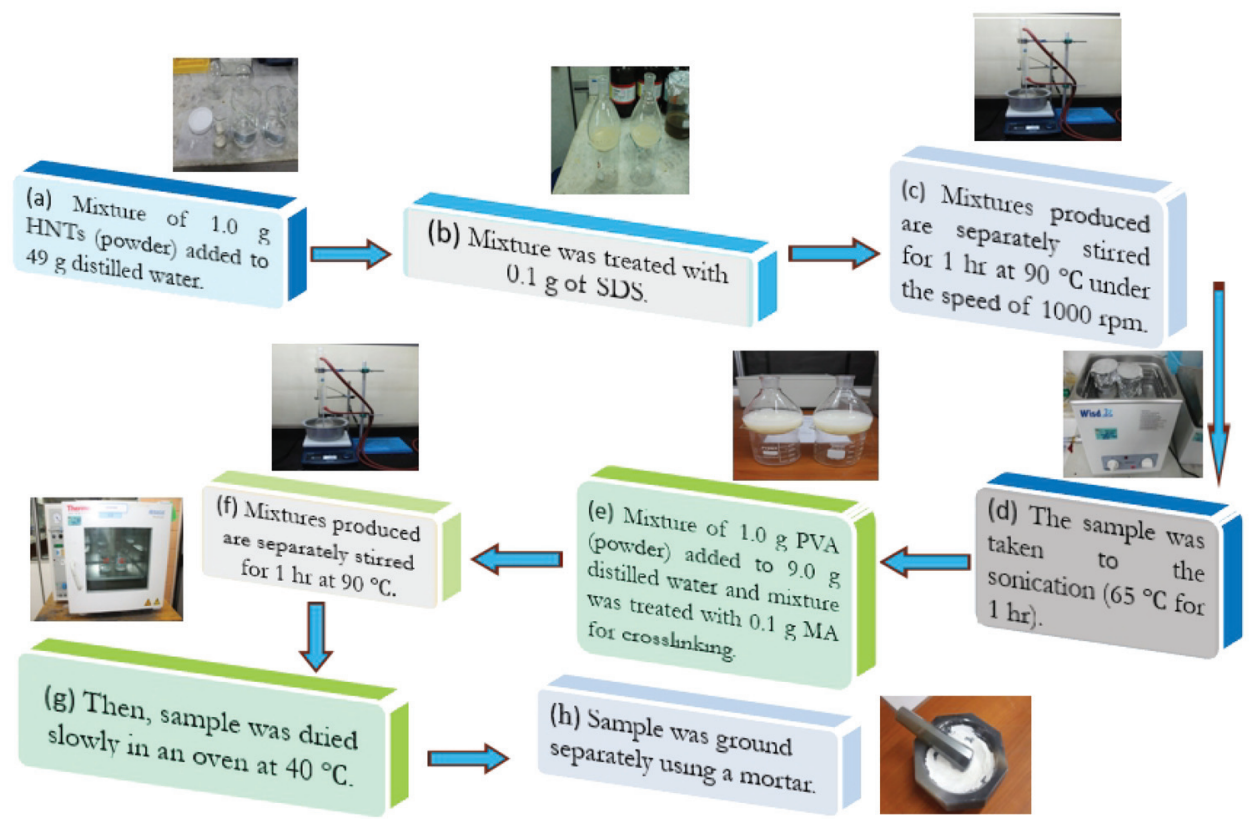

FIGURE 1. Procedure of crosslinked HNTS-PVA nanocomposites using MA

in the range of $4000-650 \mathrm{~cm}^{-1}$ wavenumber at a resolution of $0.4 \mathrm{~cm}^{-1}$. The samples were dried at $40^{\circ} \mathrm{C}$ for $12 \mathrm{hr}$ prior in an air-circulating oven. HNTs were ground thoroughly with $\mathrm{KBr}$ at approximately $1-3 \%$ by weight and pressed into a 1 -mm thickness pellets.

Thermogravimetric analysis (TGA) (Model Q600, TA Instrument, New Castle, DE) was used to characterize the thermal properties of all samples. Prior to using the samples, they were dried at $40^{\circ} \mathrm{C}$ for $12 \mathrm{hr}$ prior in an air-circulating oven. The range of the temperature of all TGA tests was between 25 and $800^{\circ} \mathrm{C}$ under atmospheric nitrogen at a flow rate of $60 \mathrm{ml} / \mathrm{min}$ and at a scanning rate of $10^{\circ} \mathrm{C} / \mathrm{min}$.

Differential scanning calorimetry (DSC) (Model Q2000, TA Instrument, New Castle, DE) was used to analyse the glass transition temperature $\left(T_{g}\right)$, melting temperature $\left(T_{m}\right)$, enthalpy of fusion $\left(\Delta H_{f}\right)$ and crystallinity of PVA, HNTs-PVA, and their corresponding MA crosslinked samples. The samples are dried at $105^{\circ} \mathrm{C}$ for $12 \mathrm{hr}$ in an oven prior to conducting the test. All DSC analyses were performed nitrogen environment where the nitrogen flows at rate of $50 \mathrm{ml} / \mathrm{min}$ and temperatures between -20 and $250^{\circ} \mathrm{C}$ at a scanning rate of $10^{\circ} \mathrm{C} / \mathrm{min}$.

\section{RESULTS AND DISCUSSION}

\section{HNTS INDIVIDUALIZATION}

HNTs are naturally occurred material as small tabular forms of an average diameter of $30 \mathrm{~nm}$. The HNTs used in this research was natural and unprocessed. Therefore, for individualization, many separation techniques were employed such as highspeed mechanical stirring, ultrasonication, treated with a non-ionic surfactant and changing the $\mathrm{pH}$ solution. The HNTs clusters are broken by a high-speed mechanical stirring shear force. The ultrasonication could be performed at an intense and high-frequency sound which is consisted of regions of high and low pressure that move through a material as waves. By this technique, each tiny portion of liquid vibrates in response to these pressure fluctuations which results in breaking of the clusters of HNTs (Qiu 2012). SDS was used as a dispersant to improve the separation of HNTs (Karatepe 2003).

The separation of HNTs is mainly dependent on manipulating the $\mathrm{pH}$ value. The negative charge HNTs on the basal or 'face' surface cannot be altered while the charge on crystal edges are subjected to the $\mathrm{pH}$ of the ambient environment. The edge surface of amphoteric nature may be attributed to the protonation and deprotonation of $\mathrm{OH}$-groups which are coordinated with $\mathrm{Al}$ ions and alkaline $\mathrm{pH}$ conditions, respectively (Joussein et al. 2005). The best-reported $\mathrm{pH}$ values are at $\mathrm{pH} 7.5$ and above (Churchman \& Theng 1984). The resulted system is characterized deflocculates, and cohesion losses. In this study, a uniform and the stable HNT dispersion was obtained due to using sequentially these separation techniques. The stable HNTs dispersion is used for fabricating HNTs-PVA nanocomposites.

\section{FIELD EMISSION SCANNING ELECTRON MICROSCOPY}

Typical FESEM images of (a) HNTS-PVA nanocomposite and (b) MA crosslinked HNTs-PVA nanocomposite is shown in Figure 2 . The images clearly show that the HNTs were individualized and uniformly dispersed within the PVA or crosslinked PVA. It is important to note that the high viscosity of the PVA solution helps to individualize HNTs and prevents clustering by immobilizing them. The degree or uniformity of dispersion of the HNTs within the polymer plays an important role in its mechanical properties (Yano et al. 1997) which means that both mechanical and thermal properties of the composites would also be expected uniform (Qiu 2012). 


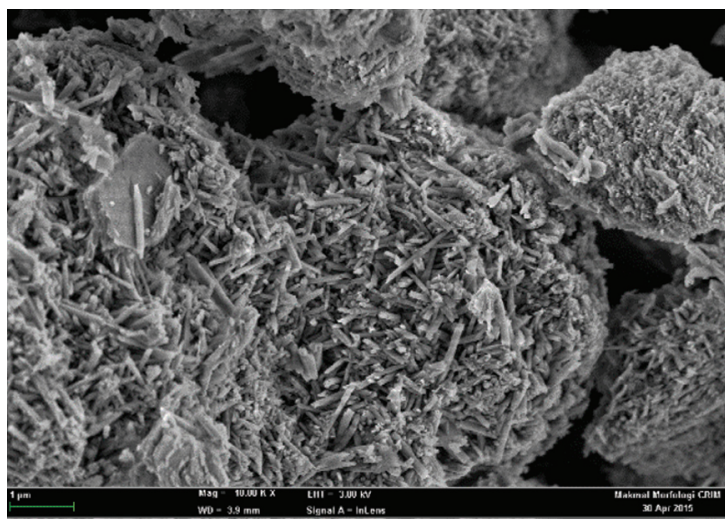

(a)

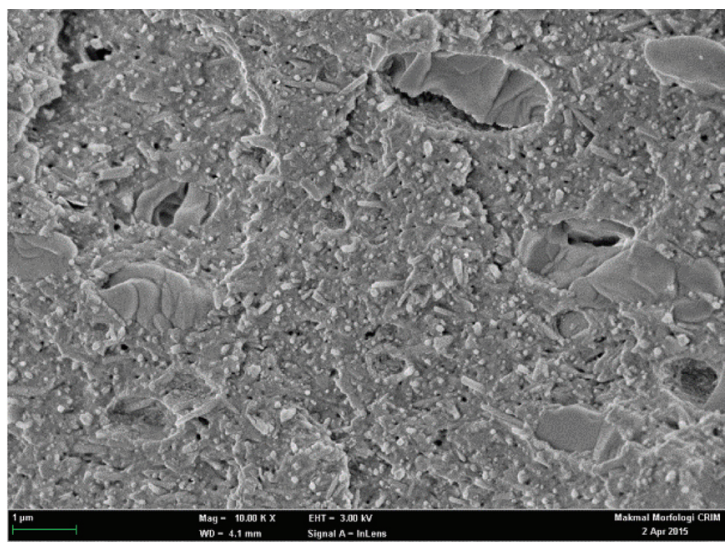

(c)

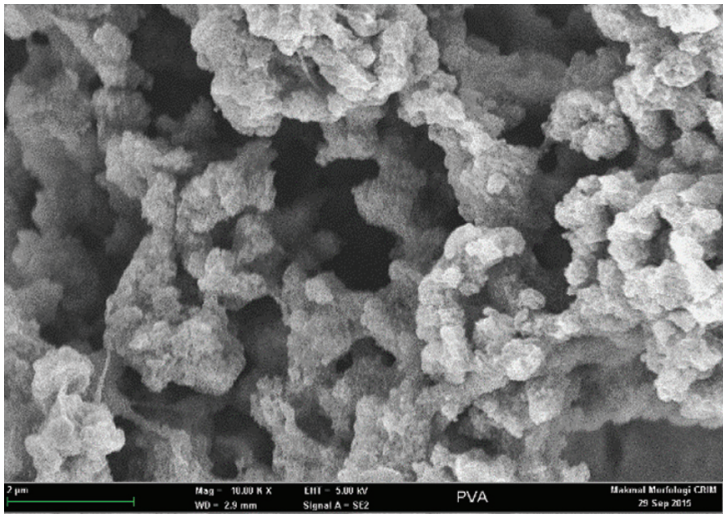

(b)

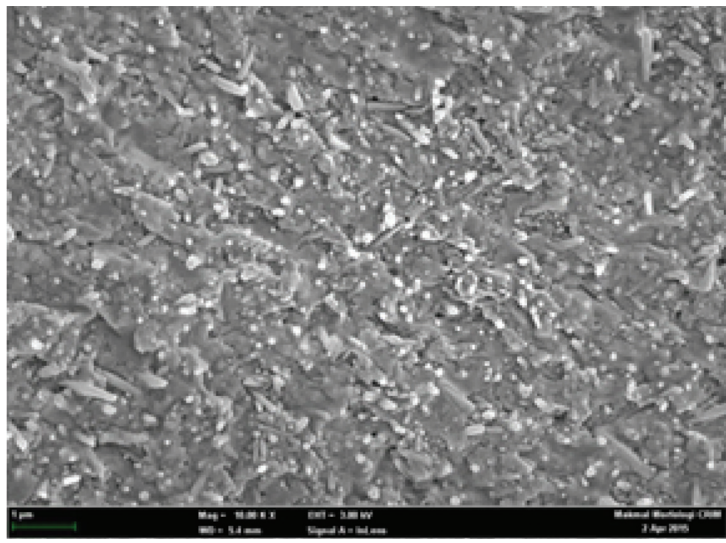

(d)

FIGURE 2. FESEM images of (a) Neat HNTs, (b) Neat PVA, (c) HNTs-PVA nanocomposites, and (d) HNTs-PVA crosslinked MA nanocomposites

\section{FOURIER TRANSFORM INFRARED SPECTROSCOPY}

The FESEM spectrum shows in Figure 3 broadband at $3500-3200 \mathrm{~cm}^{-1}$ wavenumber as a result of the $\mathrm{O}-\mathrm{H}$ stretching vibration caused by the strong intra-molecular and intermolecular hydrogen bonding (Kim et al. 2003) The absorption band observed between 3000 and $2820 \mathrm{~cm}^{-1}$

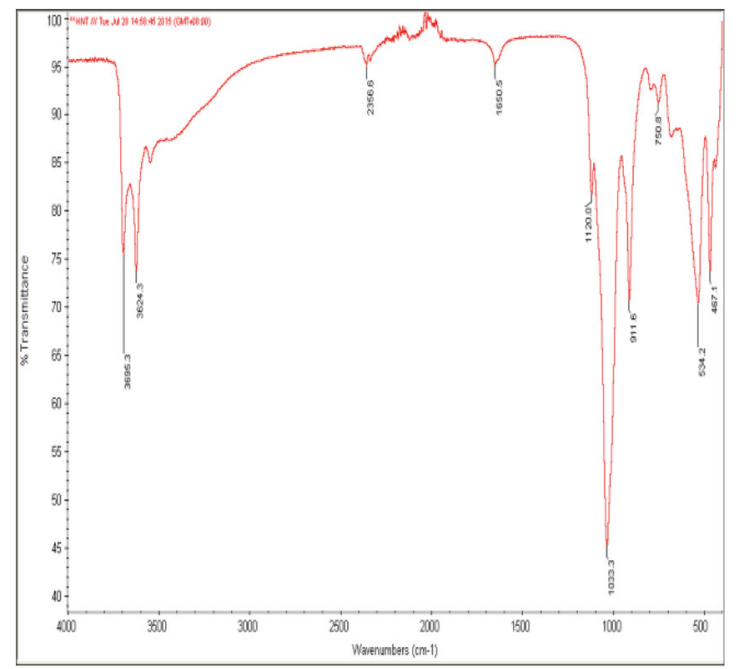

(a) wavenumbers is attributed to the stretching of aliphatic $\mathrm{C}-\mathrm{H}$ bonds (Mansur et al. 2008). This lower absorption clearly indicates a reduction in the $\mathrm{O}-\mathrm{H}$ groups and confirms the crosslinking of PVA by MA (Mansur et al. 2008) which confirms the earlier results obtained (Gohil et al. 2006) and (Mansur et al. 2008).

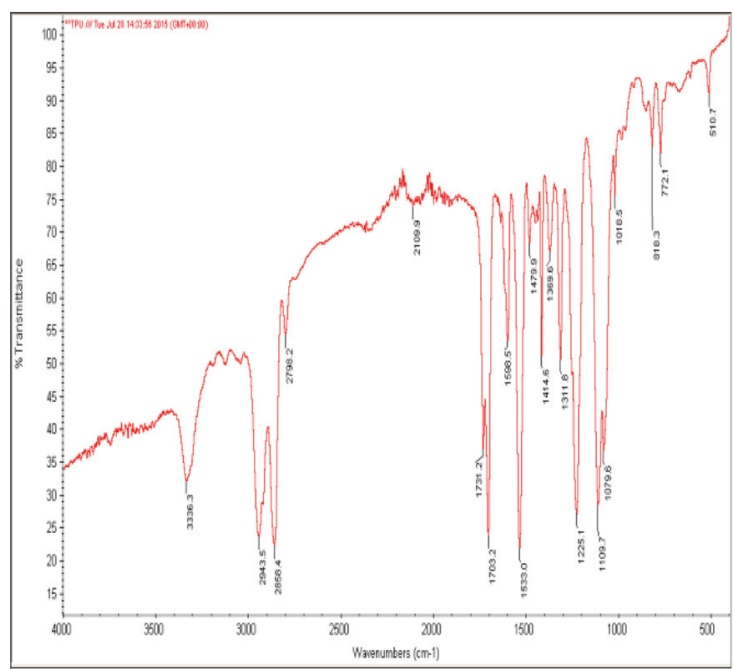

(b) 


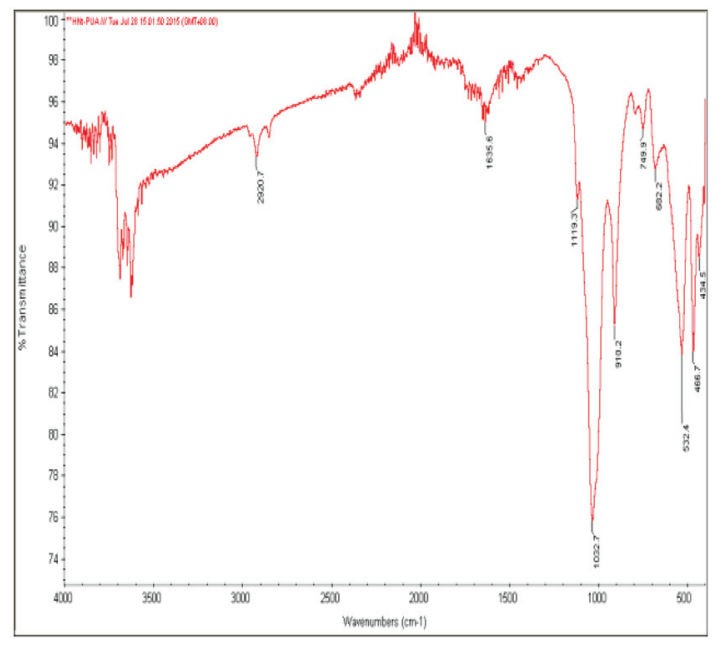

(c)

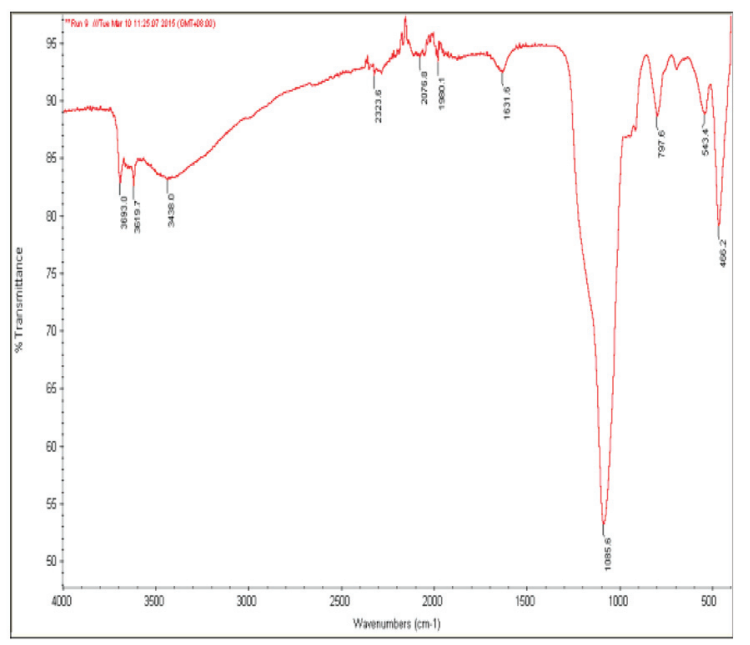

(d)

FIGURE 3. FTIR of (a) Neat HNTS, (b) Neat PVA, (c) HNTs-PVA nanocomposites, and (d) HNTs-PVA crosslinked MA nanocomposites

THERMOGRAVIMETRIC ANALYSIS-DIFFERENTIAL SCANNING CALORIMETRY

The two-step degradation of PVA was reported early as PVA first degrades into smaller molecular weight polymer at around $250^{\circ} \mathrm{C}$ by chain scission and further degrades into carbon char at temperatures above $350^{\circ} \mathrm{C}$ (Zhang et al. 2001). The results of this study confirm the earlier findings (Peng \& Kong 2007). The weight losses observed for pure HNTs at $471{ }^{\circ} \mathrm{C}, 20 \%$ at $700^{\circ} \mathrm{C}$, and $24 \%$ at $800^{\circ} \mathrm{C}$ forms about $10 \%$ and, meanwhile, confirming the higher thermal stability of HNTs (Du et al. 2006). The thermal stability enhancement after crosslinking has been observed earlier for many polymers (Chabba et al. 2005, Rodrigues et al. 2010). Figure 4 shows a typical DSC thermograms for neat HNTs, HNTs-PVA and MA crosslinked HNTS-PVA. Thermogram 6 for control Neat HNTs, HNTs-PVA, and MA crosslinked HNTs-PVA, shows $T_{m}$ of $482.9^{\circ} \mathrm{C}, 461.0^{\circ} \mathrm{C}$ and $156.0^{\circ} \mathrm{C}$, respectively (Guirguis \& Moselhey 2012). Moreover, the thermogram 6 (A) for the crosslinked PVA

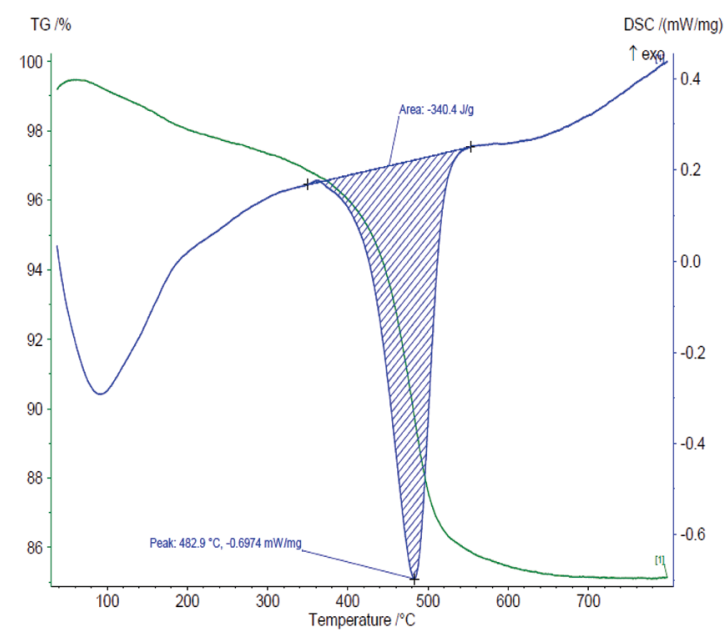

(a) shows $T_{g}$ and $T_{m}$ of $102.1^{\circ} \mathrm{C}$ and $189.7^{\circ} \mathrm{C}$, respectively. The $\Delta H_{f}$ and the crystallinity of the crosslinked PVA were 36.8 $\mathrm{J} / \mathrm{g}$ and $26.6 \%$, respectively. The lower $\Delta H_{f}$ and higher $T_{g}$ further confirm that the PVA was effectively crosslinked by MA. The higher $T_{g}$ and lower crystallinity after crosslinking are due to the restricted segmental motion of the molecules, a phenomenon commonly observed in most polymers (Kim et al. 1992; Mtshali et al. 2001). Figure 4 (b) presents typical DSC thermograms of (a) HNTs-PVA nanocomposites and (b) MA crosslinked HNTs-PVA nanocomposites. The $T_{g}$ and $T_{m}$ for the HNTs-PVA nanocomposites were observed at $90.5^{\circ} \mathrm{C}$ and $201.9^{\circ} \mathrm{C}$, respectively. The change in $T_{g}$ for nanocomposite is insignificant. While the $T_{m}$ value is about $5^{\circ} \mathrm{C}$ higher than that of control PVA, the $T_{\sigma}^{m}$ is about $1.5^{\circ} \mathrm{C}$ lower. This suggests that HNTs have the ability to lead to decrease $T_{g}$ and increase $T_{m}$ of polymers (Liu et al. 2007; Liu et al. 2009). It was observed that a similar decrease in $T_{g}$ as a result of HNTs addition (Nakamura et al. 2011) where the free volume addition was proposed.

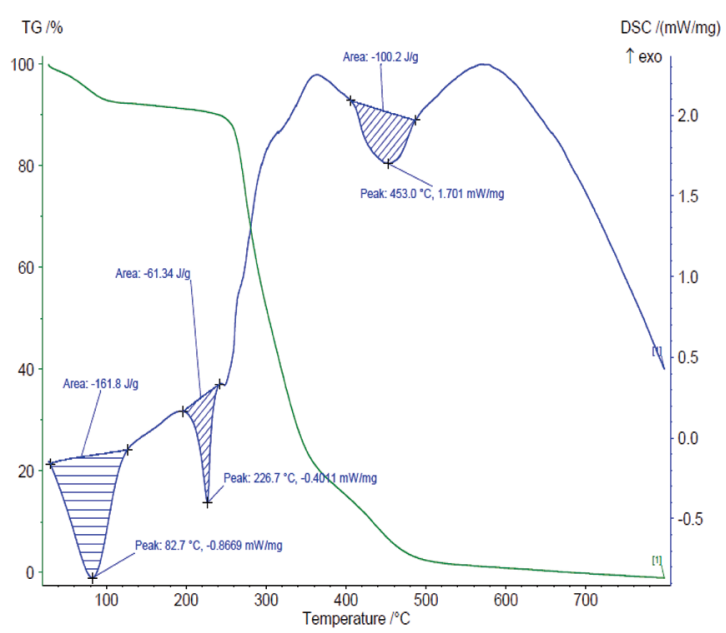

(b) 


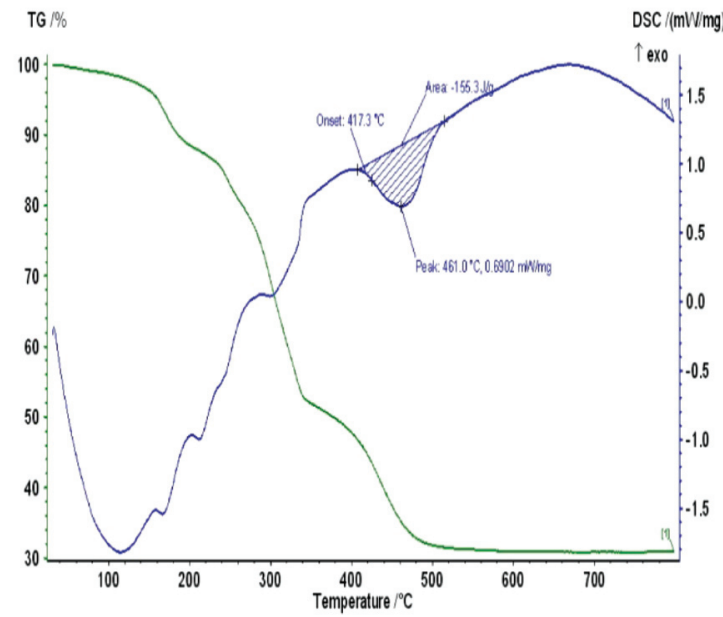

(c)

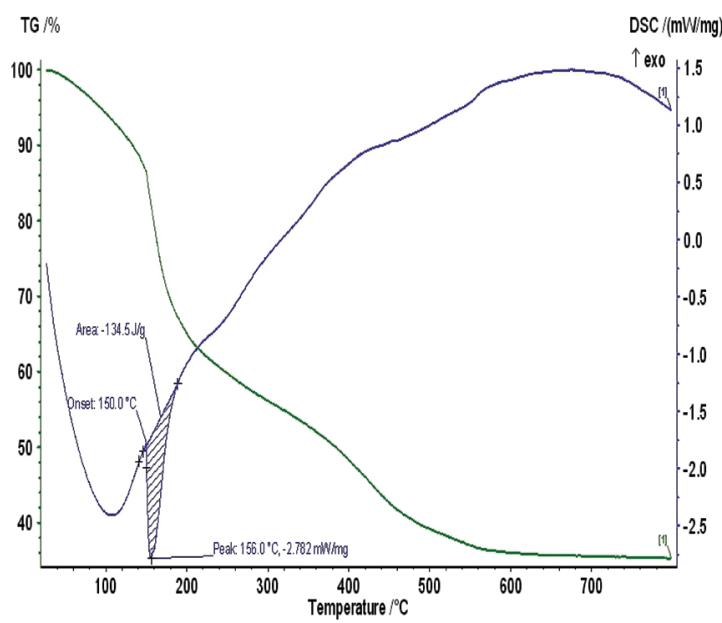

(d)

FIGURE 4. TGA-DSC of (a) Neat HNTs, (b) Neat PVA, (c) HNTs-PVA nanocomposites, and (d) HNTs-PVA crosslinked MA nanocomposites

CONCLUSION

The HNTS-PVA nanocomposites at HNTs loadings were produced by blending and casting techniques. There are several separation techniques are used such as mechanical stirring, ultrasonication, a non-ionic surfactant and desired solution $\mathrm{pH}$ to individualize HNTs and obtain stable HNTs dispersion. A close investigation to the FESEM images suggests that HNTs were uniformly dispersed in PVA and MA crosslinked PVA. The spectra obtained by FTIR suggests that PVA is more likely crosslinked using the crosslinker MA and sulfuric acid as catalyst. It is also concluded that both PVA and HNTs-PVA nanocomposites exhibited higher thermal stability after crosslinking. The higher thermal stability is attributed to HNTs loading and to the PVA-based nanocomposites. The DSC results clearly suggest that HNTs loading causes a reduction in $T_{g}$ as well as crystallinity while increasing the $T_{m}$ of PVA. Crosslinking of PVA resulted in higher $T_{g}$, lower $T_{m}$ and lower crystallinity as was expected.

\section{REFERENCES}

Ahmad, M.A.F., Nuawi, M.Z., Mohamed, N.F., Wahid, Z. \& Dirhamsyah, M., 2016. The study of polymer material characterisation Using MZN statistical analysis method. Jurnal Kejuruteraan 28: 9-18.

Chabba, S., Matthews, G.F. \& Netravali, A.N. 2005. Green composites using cross-linked soy flour and flax yarns. Green Chemistry 7(8): 576-581.

Churchman, G.J. \& Theng, B.K.G. 1984. Interactions of halloysites with amides: mineralogical factors affecting complex formation. Clay Minerals 19(2): 161-175.

Chang, P. R., Xie, Y., Wu, D. \& Ma, X. 2011. Amylose wrapped halloysite nanotubes. Carbohydrate Polymers 84(4): 1426-1429.

Deen, I. \& Zhitomirsky, I. 2014. Electrophoretic deposition of composite halloysite nanotube-hydroxyapatitehyaluronic acid films. Journal of Alloys and Compounds 586: S531-S534.
Deng, S., Zhang, J., Ye, L. \& Wu, J. 2008. Toughening epoxies with halloysite nanotubes. Polymer 49(23): 5119-5127.

Du, M., Guo, B. \& Jia, D. 2006. Thermal stability and flame retardant effects of halloysite nanotubes on poly (propylene). European Polymer Journal 42(6): 13621369.

Du, M., Guo, B., Lei, Y., Liu, M. \& Jia, D. 2008. Carboxylated butadiene-styrene rubber/halloysite nanotube nanocomposites: interfacial interaction and performance. Polymer 49(22): 4871-4876.

Gohil, J.M., Bhattacharya, A. \& Ray, P. 2006. Studies on the crosslinking of poly (vinyl alcohol). Journal of Polymer Research 13(2): 161-169.

Guirguis, O.W. \& Moselhey, M.T. 2012. Thermal and structural studies of poly (vinyl alcohol) and hydroxypropyl cellulose blends. Natural Science 4(1): 57.

Guo, B., Lei, Y., Chen, F., Liu, X., Du, M. \& Jia, D. 2008. Styrene-butadiene rubber/halloysite nanotubes nanocomposites modified by methacrylic acid. Applied Surface Science 255(5): 2715-2722.

Jian, S. \& Ming, S.X. 1987. Crosslinked PVAPS thin-film composite membrane for reverse osmosis. Desalination 62: 395-403.

Joussein, E., Petit, S., Churchman, J. Theng, B., Righi, D. \& Delvaux, B. 2005. Halloysite clay minerals-a review. Clay Minerals 40(4): 383-426.

Karatepe, N. 2003. Adsorption of a non-ionic dispersant on lignite particle surfaces. Energy Conversion and Management 44(8): 1275-1284.

Kim, J.H., Moon, E.J. \& Kim, C.K. 2003. Composite membranes prepared from poly ( $\mathrm{m}$-animostyrene-covinyl alcohol) copolymers for the reverse osmosis process. Journal of Membrane Science 216(1): 107120.

Kim, Jin Hong, Ju Young Kim, Young Moo Lee \& Kea Yong Kim. 1992. Properties and swelling characteristics of cross-linked poly (vinyl alcohol)/chitosan blend 
membrane. Journal of Applied Polymer Science 45(10): 1711-1717.

Liu, M., Guo, B., Du, M., Cai, X. \& Jia, D. 2007. Properties of halloysite nanotube-epoxy resin hybrids and the interfacial reactions in the systems. Nanotechnology 18(45): 455703.

Liu, M., Guo, B., Du, M., Chen, F. \& Jia, D. 2009. Halloysite nanotubes as a novel $\beta$-nucleating agent for isotactic polypropylene. Polymer 50(13): 3022-3030.

Liu, M., Guo, B., Du, M. \& Jia, D. 2007. Drying induced aggregation of halloysite nanotubes in polyvinyl alcohol/ halloysite nanotubes solution and its effect on properties of composite film. Applied Physics A 88(2): 391-395.

Lvov, Y. \& Abdullayev, E. 2013. Functional polymer-clay nanotube composites with sustained release of chemical agents. Progress in Polymer Science 38(10): 16901719.

Majumdar, S. \& Adhikari, B., 2006. Polyvinyl alcohol: A taste sensing material. Sensors and Actuators B. Chemical 114(2): 747-755.

Mansur, H.S., Sadahira, C.M., Souza, A.N. \& Mansur, A.A. 2008. FTIR spectroscopy characterization of poly (vinyl alcohol) hydrogel with different hydrolysis degree and chemically crosslinked with glutaraldehyde. Materials Science and Engineering: C 28(4): 539-548.

Marney, D.C.O., Russell, L.J., Wu, D.Y., Nguyen, T., Cramm, D., Rigopoulos, N., Wright, N. \& Greaves, M. 2008. The suitability of halloysite nanotubes as a fire retardant for nylon 6. Polymer Degradation and Stability 93(10): 1971-1978.

Mtshali, T.N., Krupa, I. \& Luyt, A.S. 2001. The effect of cross-linking on the thermal properties of LDPE/wax blends. Thermochimica Acta 380(1): 47-54.

Nakamura, R., Netravali, A.N. \& Hosur, M.V. 2011. Effect of halloysite nanotubes on tensile properties and interfacial property between carbon fiber and epoxy resin. $18^{\text {th }}$ International Conference on Composite Materials: 21-26.

Nakamura, R., Netravali, A.N., Morgan, A.B., Nyden, M.R. \& Gilman, J.W. 2013. Effect of halloysite nanotubes on mechanical properties and flammability of soy protein based green composites. Fire and Materials 37(1): 75-90.

Ning, N.Y., Yin, Q.J., Luo, F., Zhang, Q., Du, R. \& Fu, Q. 2007. Crystallization behavior and mechanical properties of polypropylene/halloysite composites. Polymer 48(25): 7374-7384.

Pasbakhsh, P., Ismail, H., Fauzi, M.A. \& Bakar, A.A. 2010. EPDM/modified halloysite nanocomposites. Applied Clay Science 48(3): 405-413.

Peng, Z. \& Kong, L.X. 2007. A thermal degradation mechanism of polyvinyl alcohol/silica nanocomposites. Polymer Degradation and Stability 92(6): 1061-1071.

Qiu, K. 2012. Biobased and Biodegradable Polymer Nanocomposites. Cornell University.

Rodrigues, F.T., Martins, V.C. \& Plepis, A.M. 2010. Porcine skin as a source of biodegradable matrices: alkaline treatment and glutaraldehyde crosslinking. Polímeros 20(2): 9297.
Rong, R., Xu, X., Zhu, S., Li, B., Wang, X. \& Tang, K. 2016. Facile preparation of homogeneous and length controllable halloysite nanotubes by ultrasonic scission and uniform viscosity centrifugation. Chemical Engineering Journal 291: 20-29.

Takip, K.M., Markom, M. \& Sulaiman, M.Y.M. 2015. Solvent extraction of light rare earths from acidic medium by Di-(2-ethylhexyl) phosphoric acid in kerosene. Jurnal Kejuruteraan 27: 57-62.

Yano, K., Usuki, A. \& Okada, A. 1997. Synthesis and properties of polyimide-clay hybrid films. Journal of Polymer Science Part A: Polymer Chemistry 35(11): 2289-2294.

Ye Ye, Y., Chen, H., Wu, J. \& Ye, L. 2007. High impact strength epoxy nanocomposites with natural nanotubes. Polymer 48(21): 6426-6433.

Yeom, C.K. \& Lee, K.H. 1996. Pervaporation separation of water-acetic acid mixtures through poly (vinyl alcohol) membranes crosslinked with glutaraldehyde. Journal of Membrane Science 109(2): 257-265.

Zhang, J., Mungara, P. \& Jane, J.L. 2001. Mechanical and thermal properties of extruded soy protein sheets. Polymer 42(6): 2569-2578.

Zhang, Y., Zhu, P.C. \& Edgren, D. 2010. Crosslinking reaction of poly (vinyl alcohol) with glyoxal. Journal of Polymer Research 17(5): 725-730.

Zhou, W.Y., Guo, B., Liu, M., Liao, R., Rabie, A.B.M. \& Jia, D. 2010. Poly (vinyl alcohol)/halloysite nanotubes bionanocomposite films: properties and in vitro osteoblasts and fibroblasts response. Journal of Biomedical Materials Research Part A 93(4): 15741587.

*Tayser Sumer Gaaz

Department of Machinery Equipment Engineering

Techniques,

Technical College Al-Musaib, Al-Furat Al-Awsat Technical

University,

Al-Musaib, Babil, Iraq

Emad Kamil Hussein

Department of Pumps Engineering Techniques,

Technical College Al-Musaib, Al-Furat Al-Awsat Technical University,

Al-Musaib, Babil, Iraq

Ahmed A. Al-Amiery

Energy and Renewable Energies Technology Centre,

University of Technology

Baghdad, Iraq

*Corresponding author; email: taysersumer@gmail.com

Received Date: $9^{\text {th }}$ June 2017

Accepted Date: $4^{\text {th }}$ October 2017

In Press date: $15^{\text {th }}$ December 2017

Published date: $31^{\text {st }}$ December 2017 
